\title{
Stapleless laparoscopic splenectomy in haematological disorders using LigaSure
}

\author{
Aly El-Anwar, MD; Osama Fouad, MD; Amr Abdel Nasser, $M D$; \\ Mohey Elbanna, $M D$ \\ Department of General Surgery, Ain Shams University
}

\begin{abstract}
Both technical and technological advances over the past few years have made laparoscopic splenectomy $(L S)$ more feasible and acceptable. Intraoperative bleeding is the main complication and cause of conversion during LS. Different hemostatic techniques are used for vascular control. In this study, we evaluate LigaSure vessel sealing system as the sole instrument in addition to the lateral approach for achieving a safe vascular control.

Eleven patients with hematological disorders of the spleen were enrolled in this 2 year study for LS at Ain Shams University Hospitals. Eight patients had idiopathic thrombocytopenic purpura (ITP), two patients with hereditary spherocytosis and one patient with Evan's syndrome.

In all patients the LigaSure vessel sealing system with lateral approach was used to achieve safe vascular control. The patients were 6 females and 5 males, their age ranging between 1723 years (Median= 20 yrs). The intraoperative blood loss, need for blood transfusion, operative time, post-operative complications and hospital stay as well as the cost were evaluated.

Nine cases were successfully performed laparoscopically with two conversions due to hilar bleeding. In all but two patients (converted patients) the intra-operative blood loss was less than 100ml (range 50-100ml) with no need for blood transfusion.

The operative time range was 70-100 minutes (median 85 minutes). There were no mortalities in our series. The average hospital stay was 4 days (range 3-5 days), and apart from minor wound infection, no post operative complications were recorded.

Stapleless LS using LigaSure vessel sealing system with the lateral approach is a safe procedure to carry out laparoscopic splenectomy.
\end{abstract}

\section{Introduction :}

Laparoscopic splenectomy (LS) is considered the gold standard for the treatment of hematological disorders of the spleen in adult and pediatric patients. ${ }^{1}$ It is a safe and effective technique resulting in less postoperative pain, shorter hospital stay, and faster functional recovery than open splenectomy. ${ }^{2}$ Furthermore, perioperative morbidity of the laparoscopic approach is significantly lower. ${ }^{3}$

Conversion rates are reported to be between 2 and $10 \%$ in major series and splenomegaly or uncontrolled bleeding from splenic hilum are the main causes of conversion. ${ }^{4,5}$ The approach to hilar vessels is sometimes cumbersome due to vascular hazard and rich blood supply, especially when the tail of the pancreas is barely adhesive to vascular pedicles or the main branches are divided far away from the spleen. ${ }^{6}$ Dissection without splenic traction is recommended to avoid incidental hemorrhage due to fragile parenchyma, which is difficult to treat during laparoscopy. ${ }^{6}$ In some series, the average intraoperative blood loss is high. Thus, hemostasis has to be considered a fundamental step during laparoscopic splenectomy. ${ }^{7}$

Several techniques for helping to control splenic vessels have been developed, such as hand assistance or preoperative splenic artery embolization. ${ }^{8}$ Clips, sutures, and monopolarbipolar and ultrasound coagulation have been used as hemostatic methods. The LigaSure vessel sealing system (Valley lab, Boulder, CO, USA) is a new surgical device that employs an energy-based method that works by applying a precise amount of pressure and bipolar energy to the tissues, which permits sealing of the vessels, thus changing the nature of the vessel walls (collagen and elastin within the vessel walls fuse and reform into a single 
structure obliterating the lumen) and reducing the risk of hemorrhage due to easy access to the splenic hilum, furthermore, it makes dissection easier, decreasing operative time and blood loss. ${ }^{6}$

We report herein our preliminary experience with the use of LigaSure performing laparoscopic splenectomy. Procedures have been completed relying on LigaSure as the only means of achieving hemostasis. The surgical technique is described and results and potential benefits are discussed.

\section{Patients and methods:}

A total of 11 consecutive laparoscopic splenectomy operations were performed at Ain Shams University Hospitals in the period July 2005 - Jan 2008.

The patients were 6 females and 5 males, with an average age of 20 years (range, 17-23 yrs). Indications for splenectomy were as follows: ITP in 8 patients, hereditary spherocytosis in two patients and one patient with Evan's syndrome all patients received pneumococcal vaccine routinely Table(1).

Table (1): Patient's data and indications for surgery:

\begin{tabular}{|l|l|}
\hline No. of cases & 11 \\
\hline Sex $=$ M/F & $5 / 6$ \\
\hline Age average & 20 years (range: $17-23$ years ) \\
\hline Indications for surgery & $\begin{array}{l}\text { ITP }=8 \text { cases } \\
\text { Hereditary Spherocytosis }=2 \text { cases } \\
\text { Evan's syndrome }=1 \text { case }\end{array}$ \\
\hline
\end{tabular}

\section{Surgical technique:}

Patients were placed in the reverse trendelenberg right semilateralral position with the left side up and a flank cushion supporting the right side. The legs of the table were spread apart and the surgeon stood in between. The Camera-holding assistant stood on the patient's right side where as the second assistant stood on the patients left side.

For placement of trocars, the four-port technique Figure(1) was traditionally used. The first 10-mm trocar was used for the scope (A $30^{\circ}$ - Scope was used in all cases) and placed in the midline just above the umbilicus using open method.

After creation of pneumoperitonium the other ports were placed under vision in the left subcostal region. One 5-mm port was placed just to the left of midline, a 10 -mm port in the mid clavicular line for the LigaSure 10-mm Atlas, and the last one in the anterior axillary line.

In the case of Evan's syndrome, a fifth Port Figure(2) was placed for the liver retractor since the patient had hepatomegaly, and trocars positions were altered according to the splenic size.

The operation begins after the omentum has been thoroughly examined with a blunttip probe searching for accessory spleens. An accessory spleen was found and excised in two cases $(18.2 \%)$ as shown in Figure(3). The first step is the dissection of the lower pole of the spleen, which is gently elevated. This exposes the lower polar vessels whose hemostasis is easily achieved using LigaSure, without the need for fat dissection Figure(4). The semilateral position allows for checking both the anterior and posterior aspect of the vessels, thus reducing the risk of injury. The second step is the approach to the splenic pedicle next to the hilum, as far as possible from the pancreatic tail. Hilar vessels are sealed as close as possible to the parenchyma (the device provides few injuries to surrounding tissues) and good hemostasis is checked Figure(4). The operation proceeds with the dissection of the short gastric vessels, and finally with the division of the splenorenal ligaments up to the splenodiaphragmatic attachments. 


\section{Extraction of the spleen:}

In all our cases a $3-5 \mathrm{~cm}$ left subcostal incision was done centered on the left midclavicular line 10-mm trocar to extract the spleen, to reduce costs Figure(5). A tube drain was routinely placed in the lienalis recess for 24-48 hours.

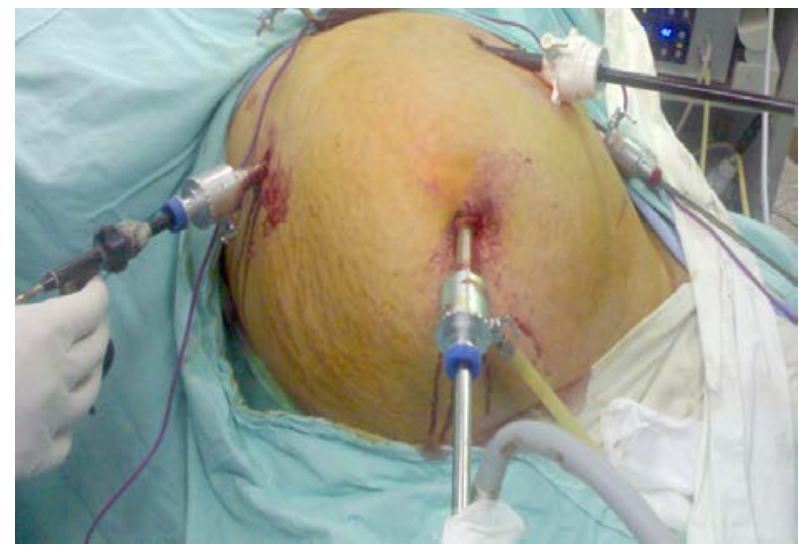

Figure (1)

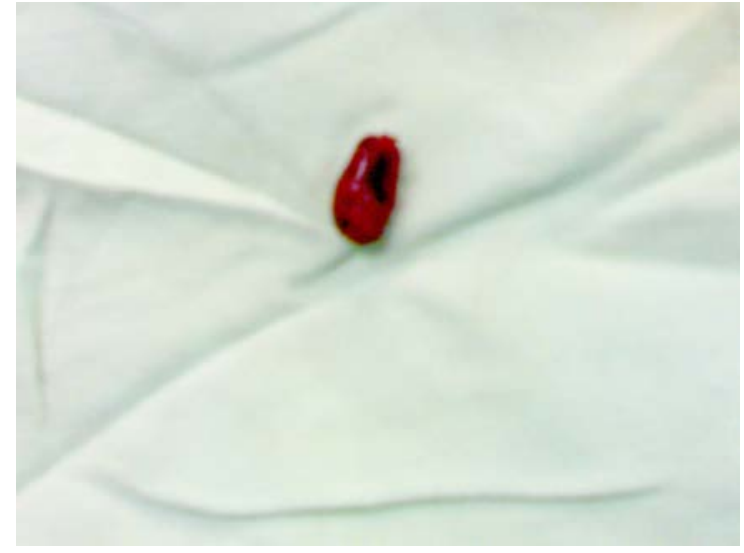

Figure (2)

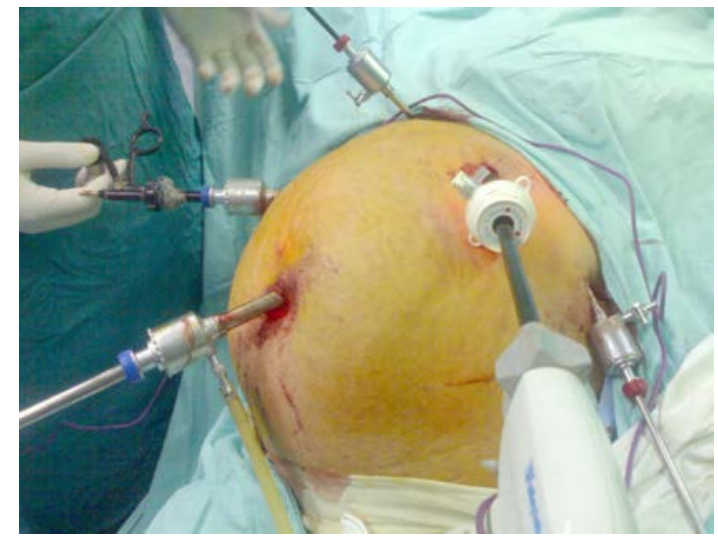

Figure (3)

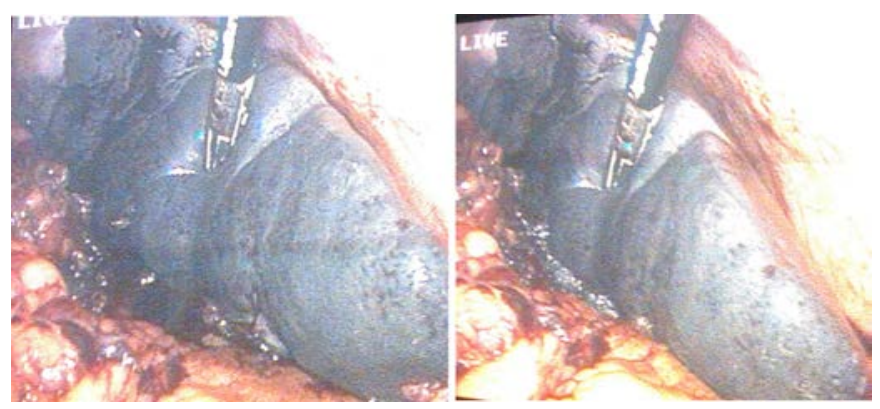

Figure (4)

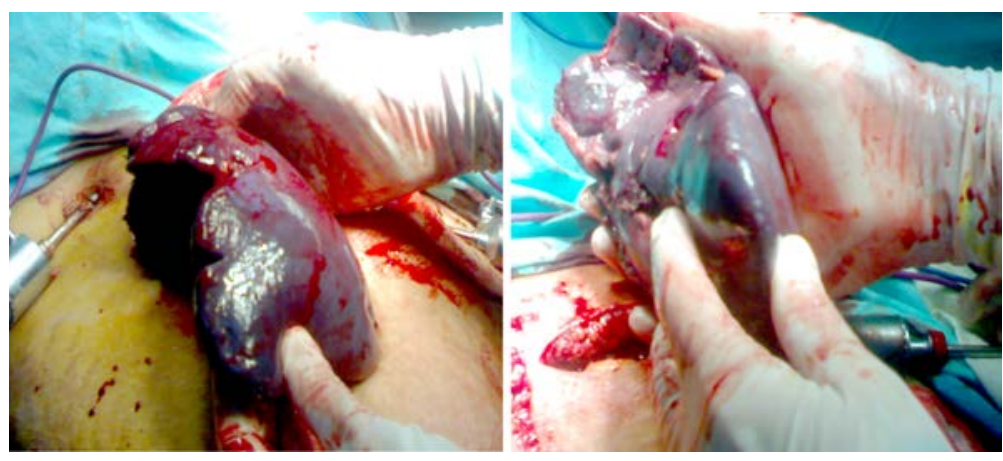

Figure (5) 


\section{Results:}

Laparoscopic splenectomy was successfully completed in 9 cases and conversion was necessary in 2 ITP cases $(18.21 \%)$ due to uncontrolled hilar bleeding Table(2).

Accessory spleens were found and removed in two patients (18.21\%) since missing accessory spleens is the major cause of failure of LS in ITP.

Intra operative blood loss was minimal in successful cases with an average blood loss of $75 \mathrm{ml}$ (range: $50-100 \mathrm{ml}$ ); none of the cases needed blood transfusion.

The average operating time was $80 \mathrm{~min}$ (range: 60-100 min) (retrieval time being excluded).

Extraction of the spleen was done through a 3-5 $\mathrm{cm}$ incision in the left subcostal region. The average postoperative hospital stay was 4 days (range: 3-5 days).

There was no operative or postoperative mortality. Only one case had minor wound infection, making the morbidity rate $9 \%$. No systemic or pneumococcal infections developed during the follow up period.

The cost of Stapleless LS includes the price of the LigaSure ${ }^{\mathrm{TM}} 10-\mathrm{mm}$ Atlas handle which is 4200 L.E. used for 10 cases.

\section{Table (2): Results}

\begin{tabular}{|l|l|}
\hline No of cases & 11 \\
\hline Successful cases & $9=(81.81 \%)$ \\
\hline Converted cases & $2=(18.21 \%)$ \\
\hline Accessory spleen & $2=(18.21 \%)$ \\
\hline Average blood loss & $75 \mathrm{ml}($ range: $50-100 \mathrm{ml})$ \\
\hline Average operative & $80 \mathrm{~min}($ range: $60-100 \mathrm{~min})$ \\
\hline Average hospital stay & 4 days (range: $3-5$ days) \\
\hline Mortality (\%) & $0 \%$ \\
\hline Morbidity $(\%)$ & $9 \%$ one case \\
\hline
\end{tabular}

\section{Discussion:}

LS is widely accepted as a safe and effective alternative to the open approach for the treatment of hematological disorders of the spleen. ${ }^{3}$ LS can be performed with minimal morbidity even in the setting of splenomegaly. Although the indication for splenectomy has not changed, the laparoscopic era has lowered the threshold for surgical referral in certain institutes. ${ }^{9}$

In the Egyptian setting, LS has not been widely applied, though it is a safe procedure in the hands of capable laparoscopic surgeons, provided that the suitable technology and equipments are available.

In our series nine cases were successfully performed laparoscopically $(81.81 \%)$ while two cases were converted to the open approach $(18.18 \%)$ due to uncontrolled hilar bleeding because of difficult splenic hilar dissection.

The conversion rate was $(7.91 \%)$ in the study carried out by Gelmini et al. (2006) Furthermore, reported conversion rates are usually between $5-10 \%$ and most conversions are related to uncontrollable bleeding from hilar vessels or capsular injury. ${ }^{6}$ However in an earlier study, Brodsky et al. (1999) reported a higher conversion rate $(18 \%) .{ }^{10}$ In our series the conversion rate was $18.18 \%$ and this can be explained by the ascendance of the learning curve.

The overlooking of accessory spleens is a major cause of LS failure especially in ITP patients. Accessory spleens were found and removed in two patients $(18.18 \%)$. This rate is comparable to the rates of $5-21 \%$ reported in various studies. ${ }^{11}$

The average blood loss in our study was 75 
$\mathrm{ml}$ in the 9 laparoscopic cases (range: 50-100 $\mathrm{ml}$ ) with no need for blood transfusion in any of the cases. Our results are close to those of Gelmini et al., (2006) ${ }^{6}$ who reported an average blood loss of $65 \mathrm{ml}$ (range: $0-100 \mathrm{ml}$ ) and markedly less than the results of earlier reports as that of Shimomatsuya and Horiuchi (1999) who recorded as average blood loss of $250 \mathrm{cc}$. Such an amount could tamper dissection and eventually lead to conversion. ${ }^{12}$

The significant reduction in blood loss is a direct outcome of the advent of new technologies for haemostatic dissection.

Several methods of achieving hemostasis and thus reducing blood loss have been developed, including clips, sutures, ultrasonic coagulation, as well as both monopolar and bipolar coagulation. Satisfactory hemostasis is essential for good results in LS. Initially, individual hilar vessels were isolated and controlled with clips or ligature prior to division. Currently, vascular isolation and en bloc transaction of the splenic pedicle are largely accomplished with an Endo-GIA stapler. Otherwise, clips are easily placed but can become dislodged and require accurate vessel dissection. Sutures can be a tedious option, and time-consuming in laparoscopic surgery. Standard bipolar and ultrasonic coagulation can be used to coagulate small blood vessels in the 1- to 3-mm range, but this technique can be slow, results in undesirable lateral thermal spread, and its use is limited in hilar vessel transaction. ${ }^{13}$

Taking into account the use of Endo-GIA staplers, proper positioning of the device for hilar vascular control requires accurate hilar dissection with meticulous skeletonization to exclude extraneous tissues, positioning as close to the spleen as possible away from the pancreas tail. Nevertheless, prominent splenic vessels, perihilar fat, and the relatively narrow jaw opening of currently available staplers may lead to bleeding from the vascular stapler line (because of incomplete hilar transaction), as frequently in the literature. ${ }^{6}$ Moreover, the tail of the pancreas can be retained between the jaws, causing pancreatic fistulas or clinical pancreatitis.

The LigaSure vessel sealing system effectively seals vessels $1-7 \mathrm{~mm}$ in diameter. ${ }^{14}$
A study by Matthews et al. (2001) compared this technology with ultrasonic coagulation, bipolar coagulation, surgical clips, and sutures. ${ }^{15}$ The results demonstrated that it creates seals that are stronger than those of other energy based ligation methods and are comparable in strength to mechanical ligation techniques. Seals created by the LigaSure system were shown to withstand a minimum of three times normal systolic pressure. LigaSure has been used on splenic and renal vessels in experimental and clinical studies, and they remained sealed without acute or chronic hemorrhages. ${ }^{16}$

The LigaSure vessel sealing system offers some advantages compared to other instruments: (a) it prevents electric hazards; (b) it ensures minimal sticking, charring, and thermal spread $(<2 \mathrm{~mm})$; (c) it reduces frequent instrument interchange because grasping, coagulating, and cutting are done at the same time, saving time and avoiding accidental capsular lesions, which cause troublesome oozing; (d) in overweight fatty patients, it makes it possible to seal lower polar vessels without perfect dissection or isolation, which can cause unnecessary bleeding; (e) it may be a cost-effective alternative for achieving hemostasis; (f) it permits easy dissection of the spleen, reducing the risk of damage to the pancreas tail (the vascular pedicle at the hilum can be sealed, staying as far away as possible from the pancreas); and (g) it is easy to use. ${ }^{6}$

The average operating time in our study was $80 \mathrm{~min}$. (range: $60-100 \mathrm{~min}$ ) which is comparable to the operative time reported in various studies. In the study carried by Romano et al. (2002)16 the average operating time was $420 \mathrm{~min}$ (range, 90-165 min) while in another study carried by Edwin et al. (2007), the median operative time was $58 \mathrm{~min}$ (range: 45135min). ${ }^{17}$

The average postoperative hospital stay was 4 days (range, 3-5) which was similar to that in the study of Romano et al. (2006) who reported 4.2 days (range, $3-7$ ). ${ }^{16}$

We had no peri-operative mortality neither it was reported in the follow up period. One patient $(9 \%)$ had a minor wound infection resolved by medical treatment. No systemic or pneumococcal infections developed during 
the follow up period.

That was close to the study carried by Gelmini et al. (2006), who recorded no mortality, a morbidity rate of $7.9 \%$, and no systemic on pneumococcal infections during the follow up period. ${ }^{6}$

In conclusion, the use of the LigaSure vessel sealing system during LS with the lateral approach is safe and effective, reduces blood loss, reduces operating time, and is a valid and cheap alternative to the use of endostaplers.

\section{References:}

1- Delaitre B, Champault G, Barrat C, Gossot D, Bresler L, Meyer C, Collet D, Samama G: Laparoscopic splenectomy for hematological disease. Study of 275 cases. French Society of Laparoscopic Surgery. Ann Chir 2000; 125:522-529.

2- Park A, Targarona EM, Trias M: Laparoscopic surgery of the spleen: state of the art. Langenbeck's Arch Surg 2001; 386: 230-239.

3- Winslow ER, Brunt M: Perioperative outcomes of laparoscopic versus open splenectomy: a meta-analysis with an emphasis on complications. Surgery 2003; 134: 647-655.

4- Walsh RM, Heniford BT, Brody F, Ponsky $\mathrm{J}$ : The ascen dance of laparoscopic splenectomy. Am Surg 2001; 67: 48-53

5- Tan M, Zheng CH, Wu HM, Chen GT, Chen IH, Zhao ZX: Laparoscopic splenectomy: The latest technical evaluation. World JGastroenterol 2003; 9: 1086-1089.

6- R. Gelmini, F. Romano, N. Quaranta,1 R. Caprotti, G.Tazzioli, G.Colombo, M. Saviano: Sutureless and stapleless splenectomy using radiofrequency. Surg Endosc 2006; 20: 991-994.

7- Schaarschmidt K, Kolberg-Schwerdt A, Lempe M, Saxena A: Ultrasonic shear coagulation of main hilar vessels. A 4-years experience of 23 pediatric laparoscopic splenectomies with out stapler. J Pediatr Surg 2002; 37: 614-616.

8- Park A, Birgisson G, Mastrangelo MJ, Marcaccio M, Witzke D: Laparoscopic splenectomy: Outcomes and lessons learned from over 200 cases. Surgery 2000; 128:660-667.
9- Brodsky JA, Brody GJ, Walsh RM, Malm JA, Ponsky JL: Laparoscopic Splenectomy. Experience with 100 cases. Surg Endosc 2002; 16: 851-854.

10-Brodsky FJ, Chekan EG, Pappas TN, Eubanks WS: Conversion factors for laparoscopic splenectomy for immune thrombocytpenic purpura. Surg Endosc 1999; 13: 789-791.

11-Knwon HC, Moon Ch, Cho YR, Kim MC, Kim KH, Han JY, Lee YH, Oh SY, Kim S-H, Kim J-S, Kim H-J: Prognostic factors of response to laparoscopic splenectomy in patients with idiopathic thrombocytopenic purpura. $J$ Korean Med Sci 2005; 20: 417-420.

12-Shimomatsuya T, Horiuchi T: Laparoscopic splenectomy for treatment of patients with idiopathic thrombocytopenic purpura. Comparison with open splenectomy. Surg Endosc 1999; 13: 563-566.

13-Kercher KW, Novitsky YW, Czerniach Dr, Litwin DEM: Staple line bleeding following laparoscopic splenectomy. Intraoperative prevention and postoperative management with splenic artery embolization. Surge Laparosc Endosc Percutan Tech 2003; 13: 353-356.

14-Kennedy JS, Shanahan PL, Taylor KD, Chandler JG: Highburst strength, feed-back controlled bipolar vessel sealing. Surg Endosc 1998; 12:876-878.

15-Matthews BD, Pratt BL, Backus CL, Kercher KW, Mostafa G, Lentzner A, Lipford EH, Sing RF, Heniford BT: Effectiveness of the ultrasonic coagulation shears, ligaSure vessel sealer and surgical clips application in biliary surgery: a comparative analysis. Am Surg 2001; 67: 901-906.

16-Romano F, Caprotti R, Franciosi C, De Fina S, Colombo G, Uggeri F: Laparoscopic splenectomy using ligasure. Preliminary experience. Surg Endosc 2002; 16: 16081611.

17-Edwin B, Skattum X, Rader J, Trondsen E, Buanes T: Outpatient laparoscopic splenectomy: Patient safety and satisfaction. Surg Endosc 2004; 18(9):13311334. 